\title{
¿EMPODERAMIENTO Y SUMISIÓN A DIOS? \\ LA ACCIÓN PÍA EN LAS NUEVAS MUSULMANAS \\ DEL SIGLO XXI
}

\author{
EMPOWERMENT AND SUBMISSION TO GOD? \\ SPANISH NEW MUSLIM WOMEN'S PIOUS AGENCY
}

\author{
Itzea GOICOLEA AMIANO \\ Instituto Universitario Europeo
}

Recibido: 29/7/2016

Aceptado: 07/09/2016

Para citar este artículo / To cite this article:

Goicolea Amiano, Itzea. «¿Empoderamiento y sumisión a Dios? La acción pía en las nuevas musulmanas del siglo XXI». En Nieves Montesinos Sánchez y Beatriz Souto Galván (coords.), Laicidad y creencias. Feminismo/s, 28 (diciembre 2016): 191-211, DOI: $10.14198 /$ fem.2016.28.08

Para enlazar con este artículo / To link to this article:

http://dx.doi.org/10.14198/fem.2016.28.08

\section{Resumen}

La 'agencia' o la capacidad de decisión y acción ha constituido un tema central en el seno de los estudios y el activismo feminista. Tomando como punto de partida la propuesta de Saba Mahmood este artículo tiene como objetivo, por un lado, mostrar la modalidad de acción pía en varias mujeres españolas conversas al islam y, por otro, valorar en términos feministas la agencia de estas mujeres que conciben su libertad a partir del sometimiento a Dios. Se argüirá que existe la necesidad de deconstruir el sesgo liberal y secular del concepto de agencia que el feminismo hegemónico ha naturalizado, así como de entender la capacidad de acción más allá del binarismo de reproducción patriarcal versus resistencia. Así, se esbozarán las principales características epistemológicas y corporales de la modalidad de acción pía, en las que el cuerpo constituye mucho más que un signo. La conclusión apuntará que si bien el marco en 
el que se gestan los discursos de género píos son patriarcales, su capacidad de acción tiene una dimensión empoderadora que lleva a estas mujeres a rechazar y negociar ciertas premisas y situaciones de desigualdad en las relaciones de género.

Palabras clave: Agencia, musulmanas, conversas, feminismo, piedad.

\begin{abstract}
Agency has constituted a key concept within feminist studies and activism. Building on Saba Mahmood's suggestion, this article seeks to show the pious modality of action in several Spanish new Muslim women, on the one hand, and to assess the agency of these women who conceive their freedom in the act of submission to God from a feminist standpoint, on the other. I will hold that the liberal and secular biases that the concept of agency that hegemonic feminism has naturalized need to be deconstructed, and that agency needs to be acknowledged beyond the dichotomy of patriarchal reproduction via-à-vis resistance. I will thus outline the main epistemological as well as corporal features of the pious modality of action, in which the body functions as much more than a mere sign. The conclusion will suggest that even though the framework in which the pious gender discourses are produced is indeed patriarchal, these women's agency has an empowering dimension that leads them to reject and negotiate certain premises and situations in which gender inequalities (may) take place.
\end{abstract}

Keywords: Agency, muslims, women converts, feminism, piety. 


\section{INTRODUCCIÓN}

[A]l convertirse, las mujeres ejercen agencia, de forma valiente y decisiva, al ir contra la corriente que marca su entorno, familia y cultura y al optar por algo extraño y diferente.

(Badran 202)

Margot Badran atribuye 'agencia' a las nuevas musulmanas que abrazan, junto con la fe, la 'extrañez' y la 'diferencia' que el islam representa en su entorno no musulmán. En el contexto occidental actual, la conversión de una mujer española adquiere significados sociales y simbólicos en que la intersección de juicios islamófobos y patriarcales que afectan e históricamente han significado a las musulmanas y sus cuerpos como lo abyectamente diferente operan con fuerza (Ver Del Olmo 2000 y 2001; Zine; Mijares y Ramírez). Desde esta perspectiva, las retornadas al islam ejercen su capacidad de decisión y acción de manera audaz al enfrentarse a la normatividad antiislámica. Este artículo, que tiene como objetivo reflexionar en torno a la agencia de algunas nuevas musulmanas españolas cuya conversión ha ido acompañada de la adopción de la piedad como guía y objetivo vital y espiritual, sin embargo, sugerirá una definición de agencia que trascienda el binarismo de la lógica de represión versus subversión que subyace a la definición que los feminismos seculares han establecido; señalaré, así pues, que la capacidad de ser sujeto agente también se halla en la vivencia de las normas y no solo en la resistencia a las mismas.

Siguiendo las aportaciones de Saba Mahmood en Politics of Piety, a lo largo de las siguientes páginas argüiré que la capacidad de decisión y acción puede entenderse como un todo en el que se distinguen diferentes modalidades, como la pía, que no tienen por qué ajustarse a lo que los feminismos seculares de raigambre liberal han solido denominar como agencia. Hacia el final del artículo valoraré en términos feministas la modalidad de acción pía, pero antes de acometer tal evaluación esbozaré las principales características de la misma. Para ello, desligaré el concepto de agencia de la ideología liberal y secular; y la conceptualizaré como formación ética y como (auto)construcción disciplinaria 
en-carnada y generizada. Asimismo, sostendré que la transformación activa y performativa que da lugar a la agencia de unas mujeres que han abrazado el islam siendo adultas es política y que su modalidad de acción pía debe ser entendida y reconocida como tal para poder realizar un acercamiento crítico en términos feministas.

Frecuentemente, el estudio de las religiones se ha realizado desde postulados seculares, es decir, desde una posición epistemológica dispar que ha solido esencializar y encasillar lo religioso como lo opuesto a la modernidad y la antítesis del pensamiento crítico, lúcido y digno de reconocimiento. De esta manera, «un autor que se identifique como musulmán practicante o militante (...) difícilmente acaba siendo reconocido como intelectual, dado que su compromiso invalidaría el principio de que 'el verdadero intelectual es un ser secular'» (Moreras 19). La naturalización de los presupuestos seculares ha llevado, a veces, a obviar que son históricos, contingentes y, por tanto, no universales. También ha dado forma a unas herramientas analíticas sesgadas que no permiten comprender modos de vida y de acción que se sitúan dentro de marcos religiosos. Por todo ello, resulta imperioso cuestionar la herencia histórica de la era posterior a la Ilustración que ha contribuido en gran medida a la construcción del laicismo como potencialmente liberador, mientras que lo religioso se considera inherentemente opresivo.

El presente artículo forma parte de una investigación más amplia, realizada en 2012, que se centraba en algunas mujeres españolas conversas al islam. Dicho trabajo se adentraba en el proceso de conversión, en la formación identitaria y en los discursos islámicos y de género de cinco mujeres de perfiles, trayectorias y posiciones políticas muy dispares. Algunas de ellas eran portavoces del feminismo islámico; mientras que otras articulaban discursos que, siguiendo a la mencionada Mahmood, denominé 'píos' porque su formación como musulmanas tenía como objetivo alcanzar y encarnar la piedad, la modestia o la discreción a través del esfuerzo y la disciplina intelectual y corporal. Es en los testimonios de estas mujeres en los que me centraré en el presente trabajo. Además de sus declaraciones, me valdré de algunas anécdotas y debates en los que estas tomaban parte en el seno de las reuniones semanales de una mezquita bilbaína, que denominaré Alhambra ${ }^{1}$.

1. Las historias de vida fueron realizadas por la autora y se encuentran depositadas en AHOA-Archivo de la Memoria. Las reuniones de Alhambra, que se celebraban regularmente desde 2010, acogían tanto a personas que habían abrazado el islam posteriormente a su nacimiento como a personas interesadas en la religión islámica. En las mismas se trataban una variedad de temas, se comentaban dudas y se ponían en común algunas ideas en torno al islam. Había algunos ritos que marcaban las reuniones: para comenzar, 


\section{FORMACIÓN ÉTICA DE LAS SUJETOS PÍAS}

Desde la cosmología coránica, se dice que el ser humano en estado de naturaleza es un esclavo (o siervo) de Al-lâh ('abdal-lâh) del mismo modo que el girasol es esclavo del sol, por hallarse vinculado a él de un modo orgánico. (Prado 28)

El concepto coránico de qadr, traducible como «destino», establece que cada ser humano posee un sino trazado por Dios. Según la creencia mayoritaria ello no implica, sin embargo, caer en un fatalismo y no responsabilizarse de los propios actos: cada musulmana y cada musulmán tiene el mando de su vida, sobre todo en lo que a los hechos cotidianos y actitudinales se refiere. En el seno de marcos conceptuales seculares de raigambre liberal, los feminismos hegemónicos han ligado la noción de la capacidad de decisión y acción con el discurso de la libertad y la autonomía individual antagónico, en principio, al del sino divino. Sin embargo, en el caso de las nuevas musulmanas pías, las bases de su discurso, su identidad y su formación en tanto en cuanto sujetos se sustentan sobre la base de que su libertad se halla en la sumisión a Dios y a su destino. A continuación ilustraré formas distintas que las conversas entrevistadas tienen de gestionar dificultades y la propia conversión al islam, lo cual me permitirá ahondar en algunos elementos de la formación ética y la modalidad de agencia de las sujetos pías.

Tras varios intentos telefónicos para concertar cita para realizar la entrevista a Fadua, respondió su marido y me dijo que su mujer estaba pasando por un mal momento y que no podía entablar conversación². Semanas más tarde,

se solía recitar alguna aleya o versículo del Corán en árabe; así pues, quien quisiera recitaba ante el resto la aleya o la azora que sabía o que acababa de memorizar y deseaba compartir. Después se proseguía con la reunión, que solía durar una hora y media o dos horas. Para terminar, se volvía a recitar Corán y se realizaban súplicas, invocaciones, se pedía el perdón de Dios y se procedía a agradecer al Altísimo. El ambiente era distendido y participativo. En las reuniones a las que yo asistí ellas fueron mayoría y también más participativas. Algunas personas, normalmente mujeres, solían ya cocinar ya comprar pasteles y bollería, que se tomaban durante la reunión junto a un rico té moruno. También eran estas las que preparan la infusión y colocaban la comida en bandejas y platos, servían y recogían las mesas al final de cada reunión. El hombre encargado de liderar las reuniones solía barrer el suelo y preguntar si hacía falta ayuda para organizar la merienda, pero la estricta segregación sexual que se intentaba mantener rompía, a veces, con la espontaneidad y favorecía la división sexual de las tareas.

2. Fadua es una mujer de cincuenta y un años, valenciana de nacimiento y asentada desde hace muchos años en el País Vasco. Se convirtió al islam en 1989 cuando se casó con su todavía hoy marido, un árabe involucrado en la gestión de la mezquita Alhambra, con quien tiene cinco hijos e hijas. Fadua suele acudir a la mezquita los viernes, con ocasión

Feminismo/s 28, diciembre 2016, pp. 191-211 
ella me explicó que no se había sentido con la fuerza de hablar por teléfono porque la habían despedido del trabajo. El día de la entrevista, cuando le pregunté cómo lo llevaba, Fadua me habló de lo duro que le había resultado que la hubieran despedido: «es que me pillaste justo, me cayó... me dio un bajón, que digo: 'es que no puedo...'» (Fadua, 01/06/2012). La importancia del empleo en la trayectoria vital de Fadua es clave, ya que potenció su independencia desde muy jovencita, constituyó un estímulo para el aprendizaje de los intríngulis de variados oficios y, sobre todo, porque el empleo le ayudó a mejorar su autoconcepto a través de las positivas valoraciones que obtuvo en múltiples lugares de trabajo. Por tanto, perder su empleo debió constituir una dificultad de considerable calado.

Sin embargo, ese estado de tristeza y preocupación parecía haberse desvanecido el día de la entrevista. Fadua me explicó que, tras el primer momento de «bajón», todo fue «bien, porque bueno, yo en seguida cambio el chip, digo: bueno, voy a tomármelo con relax, voy a pasar las vacaciones de verano aqui en casa...' y nada, este martes me llamaron» (ibídem). A lo largo de la entrevista Fadua me contó varias anécdotas en las que pude comprobar su positividad y su carácter afable y alegre, y en ningún momento explicitó que la idea del destino divino la hubiera llevado a aceptar la pérdida del empleo con buen talante. Más bien, la estrategia que puso en marcha para enfrentar el problema consistió en cambiar «el chip» y en intentar ver el lado positivo del problema: podría estar tranquila y relajada, y pasar las vacaciones estivales en casa.

Otros problemas y otras estrategias son las que encuentra Ihsan, otra de las entrevistadas ${ }^{3}$. Cuando le pregunté por las reacciones ante su conversión por parte de su entorno no musulmán, me explicó que si bien la familia y las personas cercanas la aceptaron, algunos conocidos del barrio la increparon: «les ves que te están criticando, no a la cara, pero se nota cuando te están criticando o te dicen: 'quitate eso, janda! ¿Qué haces con eso?' o 'iya te has vuelto mora?', '¿tu marido te obliga, te pega...?'» (Ihsan, 12/06/2012). Ihsan se convirtió al islam un año antes de decidir cubrirse el cabello, pero los juicios islamófobos de género, que incluían insinuar que la adopción del hiyab responde a la violencia de género, los empezó a oír una vez se lo puso

del rezo comunitario, aunque no asiste a las reuniones que se organizan en Alhambra. En 2012, formaba parte de la Comisión de violencia de género de una localidad vizcaína.

3. Ihsan es una chica bilbaína de treinta y un años, casada con un árabe musulmán de nacimiento y madre de dos criaturas. En 2012 hacía aproximadamente dos años que se había reconocido como musulmana. Ihsan es una de las asiduas a las reuniones de nuevas y nuevos musulmanes que se realizan en el entorno de la mezquita Alhambra.

4. El hiyab es el velo que cubre el cabello. 
En un principio, ella mostraba incomprensión ante las acusaciones y aducía que en su casa era ella la que mandaba, un alegato que puede entenderse como un intento de romper con la imagen de sumisión que el discurso islámofobo de género le adjudica a ella y a la mayoría, si no a todas, las mujeres con hiyab. Sin embargo, los juicios le afectaban y además, consciente de su temperamento, que podía llevarla a responder de manera agresiva, Ihsan también intentó y logró, aunque de manera diferente a Fadua, cambiar de perspectiva. Ihsan acudió a Dios para pedirle que la calmara:

La verdad es que ahora ya me da igual. Y además como estuve pidiendo mucho en los rezos, porque tengo mucho carácter, bueno, tenía, porque ahora... tenía miedo de una reacción mala y yo peor. Y pues que no era plan. Y pedí a Dios que me calmara y que me ayudara a llevarlo bien. Y la verdad que lo llevo mucho mejor». (Ibídem)

A la hora de hacer frente a las reacciones de rechazo del entorno no musulmán ante las cuales temía por su respuesta, Ihsan acudió a Dios. El resultado de la estrategia de Ihsan es que ha cambiado hasta el punto en que ahora esas reacciones «le dan igual». No son pocas las ocasiones en que Ihsan ha destacado la paz y la tranquilidad que a nivel personal el islam le ha aportado; según su testimonio, los ayunos de Ramadán, incluso antes de convertirse, la calmaron y le ofrecieron paz. Además, las súplicas a Dios que Ihsan llevó a cabo para hacer frente a las reacciones de la gente de su barrio están lejos de ser una estrategia aislada; más bien, conforme va aprendiendo sobre el islam, Ihsan va adoptando e incorporando una manera de estar en la vida y de hacer frente a los problemas que se caracteriza por la piedad. En este sentido, es importante tener en cuenta que si bien la piedad se encuentra en el centro de su estrategia, también lo está su planteamiento: Ihsan quiere evitar tener una reacción «mala», porque la agresividad y la violencia no son propias de una persona pía.

La diferencia, por tanto, que se halla en las estrategias que Fadua e Ihsan ponen en marcha ante las dificultades de la vida es lo que marca, a su vez, la diversidad de modalidades de acción que las caracterizan. Mientras que la estrategia de Fadua está basada en una actitud mayoritariamente bien valorada por parte de la sociedad y los feminismos seculares, la de Ihsan encarna una actitud pía fuertemente denostada. De hecho, esta última ha sido tradicionalmente considerada la antítesis de la agencia por encarnar lo contrario a la autonomía individual que prescinde de la intercesión divina. Sin embargo, ambas parecen haber tenido éxito en sus respectivas empresas y objetivos; ambas estrategias parecen satisfacer lo suficiente a las sujetos que las emprendieron porque cumplen con el objetivo de transformar las condiciones que 
querían ser cambiadas. Por tanto, la capacidad de acción de Ihsan es funcional y es, en cualquier caso, una capacidad de acción en toda regla, aunque difiera completamente de aquella que encaja en mayor medida con lo reconocido y valorado por el feminismo secular.

La formación ética que persiguen y cultivan quienes, como Ihsan, ponen en el centro de su vida y su persona la piedad conlleva realizar un cambio, y no simplemente reconocerse como musulmana sin llevar a cabo una transformación activa. Nora admite haber cambiado a raíz de la adopción del islam, porque «adquirir ciertas creencias te cambia» (Nora, 10/07/2012) ${ }^{5}$. En cambio, Ihsan considera que la transformación a raíz de la conversión al islam es algo que va implícito en la propia asunción de la nueva religión:

No es: '¡ala! ¡Soy musulmana y Alhamdulil-Lâh [gracias a Dios]!’. Pues tienes que aprender una serie de cosas. Y sobre todo tienes que aprender por ti (...) Dios te pide que tú mismo adquieras conocimiento para que así entiendas, porque por ejemplo si dices: 'yo creo en Dios y tengo que hacer esto por esto...' No, Dios te ha dado la capacidad de entender, y contra más leas, más puedes comparar, tú mismo razonar; pero si tú no lees, no aprendes, pero si tú no sabes nada y te dicen: 'venga, ahora vamos aquí, vamos...' ¿Qué eres, un monigote? No, somos personas y tenemos que entender lo que creemos... y para entender hay que leer, hay que informarse... (Ihsan)

El conocimiento y «aplicarse», según Ihsan, la alejan de la fe ciega y de ser una persona manipulable que hace amén a lo que se le dice porque no conoce su propia religión y no hace uso de la razón. Y, aunque en esta afirmación pueda vislumbrarse una dimensión empoderadora de la modalidad de acción pía y del estudio que Ihsan realiza, algo en lo que me centraré más adelante, me gustaría hacer hincapié en que ella considera un deber formarse en el islam para poder ser una buena musulmana; y que es esta la motivación central de su esfuerzo y constancia en la memorización y el estudio de las fuentes del islam, por un lado, y lo que define su modalidad de acción pía, por otro. En este sentido, la modalidad de acción pía no puede únicamente definirse por el reforzamiento o la resistencia a las normatividades islámicas que de esta se desprenden, puesto que la normatividad «no solo se consolida o se subvierte, sino que se performativiza, se habita y se experimenta de muchas maneras» (Mahmood 21).

5. Nora es una treintañera bilbaína que entró en el islam hace aproximadamente una década. Nora no se mueve en el círculo de la mencionada mezquita y es la única de las cinco informantes cuya pareja no es musulmana. 
Para Ihsan el estudio, en general, y la memorización del Corán, en especial, constituye una forma más de la cultivación y de la disciplina que entiende que Dios recompensa en la vida eterna. Según sus propias palabras,

[t]ienes que memorizar [el Corán] en árabe y entenderlo en castellano. Es un doble trabajo. Y entonces Dios te recompensa el doble. Pone, ¿sabes? Que por ejemplo a la gente que no sabe el idioma y lo aprende Dios le recompensa el doble. (Ihsan)

Así pues, Ihsan primero recurre a la traducción de las aleyas para poder entender aquello que memoriza, y después realiza el ejercicio de memorización tanto de las palabras en árabe como de la entonación y las pausas que las reglas de recitación del Corán marcan. Ello conlleva un gran esfuerzo, tal y como admite: «es complicado, la verdad. Quiero aprender árabe, In Shah Allâh [si Dios quiere] » (Ihsan). Aprender la lengua árabe le permitiría tener acceso al mensaje divino en el idioma original en que se produjo la revelación. Una parte importante de la importancia de dicha cultivación intelectual reside en el valor que Ihsan considera que Dios concederá al esfuerzo que lleva a cabo. Ese valor y esa recompensa son las bendiciones divinas. Lograrlas es la causa y el objetivo de la transformación en la que Ihsan está inmersa.

También Elena hace del estudio del islam un principal pilar en su formación pía ${ }^{6}$. Muy aplicada, entusiasta y una gran lectora, cuando Elena se dispuso a explicarme los cinco pilares del islam o los ejes en los que se articulan las obligaciones de las personas musulmanas, mencionó cuatro de ellos y después se detuvo. Hizo una pausa larga, repasó los cuatro que me había comentado y me dijo que se le había olvidado el último; tras unos minutos le dije que no se preocupara, que era normal, que prosiguiéramos. Ella, nerviosa y frustrada porque no lograba recordar el quinto pilar, se levantó y se dispuso a ir a buscar un libro para poder recordar el pilar que le faltaba. Entonces, ante la perspectiva de que iba a cortarse el hilo de la entrevista, le pregunté si el que faltaba era el ayuno de Ramadán y, asintiendo, volvió a sentarse junto a mí. Este gesto me sirvió para comprobar la importancia que para ella tenía recordar los cinco pilares. Elena, que abrazó el islam apenas unos meses antes de la entrevista, conocía ya mucho léxico árabe relacionado con el islam, también recordaba muchos pasajes coránicos y los números de las aleyas de las que hacía mención. Como en el caso de Ihsan, la disciplina en el estudio, la memorización y la lectura de lo relacionado con el islam regía la formación de Elena como sujeto pía.

6. Elena es una vizcaína de veintisiete años que se reconoció como musulmana meses antes de realizar la entrevista. También Elena era una de las asiduas a las reuniones de Alhambra. 
La disciplina y la intencionalidad que rige la transformación que Ihsan y Elena pretenden realizar en sus propios seres posee, además, un carácter performativo. A través del empleo de frases e interjecciones islámicas en árabe, como se puede ver en las citas reproducidas, las sujetos pías constatan la concepción islámica del mundo que, al mismo tiempo, la propia reiteración contribuye a consolidar. De manera similar, la práctica de al-haya, necesaria para alcanzar la piedad, implica «ser reservada, modesta y capaz de recrear la timidez» (Mahmood 156). El hecho de «recrear» la timidez o la modestia aparece de manera clara en el testimonio de Ihsan sobre el momento en el que decidió cubrir su cabello: "yo misma empecé a tener un pudor que antes no sentía» (Ihsan). La in-corporación de al-haya, manifiesta en el hecho de empezar a sentir un pudor que no había experimentado anteriormente, entra dentro del proceso de aprendizaje pío, recatado y modesto, que la formación de sujetos pías entraña.

La in-corporación y la performatividad de la modestia y la timidez implican un aprendizaje, una repetitividad y un entrenamiento, como si de adquirir unas competencias musicales, deportivas o intelectuales se tratara; solo que, en este caso, estas competencias se sitúan en el campo ético. Desde este planteamiento, el cuerpo no puede ser considerado un mero signo, sino un modo más de lograr recrear la piedad, un instrumento que permita la adquisición de las competencias pías. Más si cabe: el cuerpo no puede entenderse como algo aislado, y debe estar sincronizado con el resto de las facetas que conforman la subjetividad pía. En un momento de la entrevista, Elena se refirió a la importancia que lo que esconde el interior tiene en comparación con lo externo. Según ella, lo interior (la pureza del espíritu, el conocimiento intelectual) tiene prevalencia sobre lo exterior (vestirse de tal o cuál manera):

Tú puedes llevar niqab, no te estoy hablando de hiyab... o sea, puedes llevar burq'a, si quieres, que si tienes el corazón negro, no vas a ir al Paraíso, ¿sabes? Me da igual que te cubras hasta los pies... que lo importante es lo que haya en tu corazón» (Elena, 24/06/2012)

Así, la coherencia entre la esfera externa (la vestimenta, el lenguaje y los gestos empleados que guiaban la ya comentada voluntad de controlar el impulsivo carácter de Ihsan ante los juicios islamófobos de género) y la interna (lo emocional e intelectual) es central en la recreación de la piedad y el cuerpo es, en este conjunto, una parte más. Tal y como sugiere Mahmood, estas sujetos parten de que el medio para conseguir llegar a la piedad lo marca la «sincronización

7. El niqab es el trozo de tela que solo deja los ojos al descubierto, mientras que el burq'a cubre también los ojos. 
de su comportamiento externo en consonancia con las intenciones internas hasta [cumplir el objetivo de] que la discrepancia entre ambas facetas se haya disuelto» (157).

Como hemos visto, las sujetos pías como Ihsan y Elena conciben la conversión como una transformación activa de la propia persona. Dicha transformación está motivada por la sumisión a Dios, que es la que guía su comportamiento, su pensamiento así como sus motivaciones diarias y sus aspiraciones futuras. Pero además, entienden que el cambio debería acaecer en el plano interno a la vez que en el externo y, de hecho, de forma sincronizada y armónica entre ambas esferas. La piedad, por tanto, es la suma de las diferentes facetas de una persona o, mejor dicho, la armonización de las diferentes partes que conforman el yo. Es decir, que la coherencia entre la apariencia pía y el espíritu pío es el objetivo que marca el trabajo personal y la modalidad de acción de estas mujeres. Como tal, la formación ética de estas mujeres no puede sino considerarse política. Lo ético, tradicionalmente considerado fuera del terreno de lo puramente político, afecta en la modalidad de acción pía muchos ámbitos; y su carácter y las consecuencias políticas son, como seguiremos viendo, importantes.

\section{EL (AUTO)CONTROL DE LAS PASIONES O EL (AUTO)CONTROL DE LA MASCULINIDAD PASIONAL}

En las relaciones de poder la sexualidad no es el elemento más sordo, sino, más bien, uno de los que están dotados de la mayor instrumentalidad: utilizable para el mayor número de maniobras y capaz de servir de apoyo, de bisagra, a las más variadas estrategias. (Foucault 126)

La formación ética y la transformación que el proceso de erigirse en sujetos pías llevan a cabo Elena e Ihsan tiene tanto una base como un impacto de género. El pudor y la recreación de la timidez comentadas, en especial, están íntimamente ligadas al género. Poco tiempo antes de la entrevista, Elena había adoptado como vestimenta un jimar oscuro que destacó le permitía marcar unos límites en las relaciones con los varones: «es una manera de que veas que soy musulmana, y de que vayas a tener también una forma de comportarte conmigo, y una atención, porque conmigo tienes unos límites que no tienes con las demás» (Elena). El discurso de género de Elena, como el de otras sujetos pías del entorno de la mezquita Alhambra, se fundamenta en asunciones patriarcales que incluyen

8. El jimar es una tela ancha y larga que cubre desde los pies hasta los muslos. 
una fuerte esencialización de los sexos y la supremacía del discurso sobre la complementariedad (jerarquizada) de los roles sexuados. En ese sentido, la segregación de los sexos se considera necesaria para mantener una castidad que sigue una lógica exclusivamente heterosexual, y que es manifiesta en el testimonio de Elena.

La manera en la que la transformación pía de Elena entronca con conceptos patriarcales que moldean su capacidad de acción resulta especialmente patente en la relación que mantiene con un hombre musulmán de nacimiento. La pareja se conoció antes de que Elena se convirtiese al islam, en una época en que, según ella, él estaba retomando su religión tras haberla descuidado durante una temporada. En el momento de la entrevista, los cambios en las vidas espirituales de ambos habían modificado las características de la relación inicial: Elena y Ahmed vivían en un mismo apartamento junto con una tercera persona y cada cual tenía su habitación; no mantenían relaciones sexuales, al contrario que cuando se conocieron; y ella tampoco se quitaba el velo delante de él. Elena me explicó cómo el sheij de Alhambra instó a la pareja a mantener ese tipo de relación durante tres meses, tiempo que ya habían excedido con creces y que iba a alargarse hasta la celebración de la boda. Según me contó, ello les permitía construir un vínculo que no estuviera basado en la pasión y limpiar las bases de su relación para hacer que fuera islámicamente correcta.

La concepción del peligro que entrañan las pasiones es profundamente pía y el nuevo pacto de piedad de la pareja guarda relación con la ya comentada disciplina que rige la formación pía. Pero además, existen en la historia de vida de Elena algunas claves que pueden arrojar mayor luz sobre el establecimiento de estas novedosas reglas del juego; que, siguiendo con lo que aquí interesa, dan sentido y forma a su capacidad de acción. De la biografía de Elena se desprende el sufrimiento que las infidelidades de su expareja le causaron y de su testimonio, la frustración y la rabia a la que la llevaba no controlar la sexualidad del que fue su novio. Ahmed, su actual pareja, se encuentra en un proceso de transformación dirigida a erigirse en sujeto pío y encarna, según Elena, lo contrario a su ex. Veamos su testimonio antes de proseguir con el análisis:

Porque yo soy súper celosa, mogollón. Mogollón. Y la primera persona con la que no he sentido celos es con él [con Ahmed] porque sé que tiene un respeto. Hacia Dios lo primero. Lo segundo hacia él. Él es el primero que le da vergüenza mirar a una tía. Le da vergüenza. A ver, por supuesto, viviendo donde vivimos, ninguno de los dos somos ciegos. Porque no somos ciegos. Y tanto en un momento dado puedo llegar a mirar yo como él. (...)

Y el hecho de la prohibición del alcohol y tal... si te dejas llevar de normal, con un par de copas es el despelote, porque te baja el inhibidor, que te quita la vergüenza de 
todo. Que es algo súper importante para un musulmán, la vergüenza, la vergüenza de uno mismo... de medir mucho lo que vas a hacer, con todas sus consecuencias. No medir por el qué va a decir la gente, tienes que mirar por tu relación entre tú y Dios, lo que digan los demás no te tiene que importar y a los demás no les tiene que importar lo que tú hagas. (Ibídem)

Elena afirma no sentir celos por primera vez en su vida debido a la vergüenza (al-haya) que tiene Ahmed, que se resume en que no mira a mujeres. Eso la hace sentirse segura, y sin embargo no menciona que la vergüenza de él sea por ella: «tiene un respeto. Hacia Dios lo primero. Lo segundo hacia él»; es decir, que es un autocontrol guiado por la piedad que se concreta en «medir mucho lo que vas a hacer, con todas sus consecuencias». Elena se adscribe a ese control y medición de las pasiones que de otra manera considera incontrolables (el «despelote»), sobre todo si existe ingesta de sustancias como el alcohol, que entiende que el islam prohíbe. Y lo hace, en primer lugar, porque es lo que considera que Dios prescribe; y, en segundo, porque dadas sus anteriores experiencias, el (auto)control de las pasiones de su pareja le aporta seguridad, confianza y un mayor bienestar. Dentro del marco del pacto de piedad con Ahmed, Elena tiene una capacidad de acción que no tenía en su anterior relación: ella es pía, y él también; ella se tapa, y él también; ella no mira a los hombres, y él no mira a las mujeres.

El control de la sexualidad que persigue Elena se sitúa dentro de un marco únicamente heterosexual y de una comprensión esencializada de los sexos, en la cual la masculinidad se concibe como inherentemente pasional y la feminidad como esencialmente atractiva. Según ella, «las mujeres como que... incitamos más a... ipues estamos mejor hechas! ¿Qué quieres que te diga...? Allâh ha tenido esa cosa con nosotras, que nos ha hecho mejores» (ibídem). Así pues, si bien para reconocer la capacidad de acción pía resulta necesario dejar de lado las herramientas conceptuales y políticas que históricamente han dejado dicha agencia al margen de toda consideración; es igual de imperioso someterla a la crítica feminista para ver los sesgos y las bases patriarcales que se consolidan a través de ella. En este sentido, no cabe duda de que el control de las pasiones sexuales que guía el pacto pío entre Elena y Ahmed consolida la heteronormatividad, el binarismo (jerarquizado) de género, la esencialización de los sexos y la monogamia exclusiva; normatividades que, por otra parte, no son exclusivas de la modalidad de acción pía. 


\section{DIMENSIONES EMPODERADORAS DE LA AGENCIA PÍA}

[E]l feminismo hegemónico trabaja de manera consciente y activa para uniformar las prioridades de la lucha feminista, pero únicamente a su imagen y semejanza (...) No podemos atender únicamente a la discriminación por razón de género, sin tener en cuenta, a la vez, las discriminaciones por razón de clase, origen, sexo, raza y religión.

Estas no deben ser tratadas como 'simples daños colaterales', dentro de un proyecto feminista superior. Es necesario tener en cuenta la interseccionalidad de las opresiones, ver cuáles son las conexiones que se llevan a cabo, por parte de quién, quién se beneficia de ello y cómo se dan en diferentes contextos, tanto históricos, geográficos como experienciales (Andújar) ${ }^{9}$

A pesar de la evidente base heteropatriarcal que rige la formación de las sujetos pías, como he ido señalando hasta el momento, en esta sección ilustraré las dimensiones empoderadoras que pueden ser reconocidas una vez se ha establecido la lógica y la modalidad de acción pía. Ahora bien, que existan ventanas de empoderamiento que permitan a estas mujeres negociar y limitar ciertos privilegios masculinos derivados del sistema sexo-género no quiere decir que su agencia sea en parte feminista; no se trata de buscar las actitudes o los elementos feministas en el seno del discurso de estas mujeres para, desde la cátedra del feministómetro, atribuirles cierta dosis o incluso el nacimiento de una conciencia feminista. Más bien, como trataré de mostrar, en el seno de la modalidad de acción pía se gestan espacios y actitudes que conllevan el cuestionamiento de algunas situaciones de desigualdad entre mujeres y hombres; y estas dimensiones empoderadoras también significan y moldean su modalidad de acción pía.

En un momento de la entrevista, Elena y yo hablamos de la coacción que algunas personas ejercen sobre otras, en general, y más concretamente sobre la insistencia que desde fuera y dentro del islam se hace en la importancia de que la vestimenta de las mujeres sea recatada. Entonces Elena mencionó que si Dios le ha dicho que no tiene por qué exigírsele nada, ella no va a permitir que eso suceda. Es decir, volviendo a la formación de las sujetos pías, estas muestran para con Dios su más absoluta sumisión, la cual se constituye como

9. Resulta imperioso destacar que el feminismo secular es muy variado y que en su seno existe una amplia amalgama de posiciones y tendencias. Hace décadas que parte del feminismo secular ha adoptado una perspectiva interseccional, tanto en el ámbito académico como en el activista. Ver al respecto Gil 259. 
única e intransferible. En las reuniones de Alhambra se comentó varias veces la libertad a la que la sumisión a Dios les había llevado, ya que siendo esta única y exclusivamente para Dios, los y las había liberado de otras sumisiones. Elena interioriza, por tanto, que la máxima autoridad que Dios encarna para ella la insta a no someterse a exigencias de ningún ser humano:

Si Allâh es el primero que me ha dicho que no se me puede exigir nada, tú no me vas a exigir nada (...) la imposición no es un camino, y está en la aya [aleya] 255 de la sura [azora] dos de al-Baqara [la Vaca]: 'no cabe coacción en la religión', pero para todo, para hombres y para mujeres. (Elena)

Aquí se introduce un elemento nuevo concerniente a la manera en que Elena aplica el mensaje divino en relación a las personas con las que se relaciona. Además de la autocultivación, del querer provocar un cambio en la propia persona (interna y externamente) en concordancia con las prescripciones divinas, según ella las entiende, en este fragmento se halla una dimensión más que añadir a la modalidad de acción pía: en el caso hipotético de que cualquier autoridad y, en el caso que nos interesa, la masculina, pretendiera imponerse sobre ella exigiéndole tal o cual cosa, el conocimiento y la cultivación que para erigirse como sujeto pía está realizando serviría a Elena para, valiéndose de los argumentos islámicos, contradecirla y desautorizarla.

Elena también mencionó la poligamia, de la que afirmó no creer que fuera congruente con el mensaje divino. Según ella, la práctica de la poligamia está sometida a ciertas condiciones. Y Elena entiende que quien tiene conciencia de Dios, temor a sus puniciones y deseo de sus bendiciones no puede pasar dichas condiciones por alto. Es decir, que la persona que sea pía y trabaje en formarse como tal a través de la sincronización de la esfera interior y exterior por y para Dios no puede sino entender que el mensaje divino desestima, desde un punto de vista moral, la poligamia. En este sentido, como en el pasaje anterior, si bien el conocimiento del islam está motivado por el trabajo que realiza en el seno del proceso de formación de sujeto ética, resulta manifiesto que puede contener algunas ventanas de empoderamiento.

[Allâh] te exhorta a que tengas una igualdad con esas mujeres... pero no solo material, también supuestamente las tienes que querer igual. Querer de sentimientos, ifijate! Entonces, moralmente es muy dificil que tú vayas a tener permiso de Allâh para que tengas cuatro mujeres. Luego tú verás lo que haces con tu vida, y solo las vas a poder tener si tu [primera] mujer te da permiso, eso lo primero. Pero si tú tienes miedo, si tienes taqua [conciencia de Dios]... tú no vas a poder tener cuatro mujeres, ¿sabes? Ni tres ni dos... ni nada. (Ibídem) 
Así pues, Elena considera que la igualdad que condiciona la práctica de la poligamia invalida, de hecho, la consecución de la propia práctica ${ }^{10}$. Es decir, que el marido sea justo con todas las esposas que tome es condición sine qua non de la poligamia, y como ella considera que es imposible lograr querer de la misma manera a más de una persona, se rompe la regla de igualdad y también la de la justicia que Elena entiende que estipula el Corán. Por tanto, Elena considera que «moralmente» es difícil lograr el permiso de Allâh para ejercer la poligamia. En el marco de la formación de las sujetos pías, es importante señalar que Elena está interesada en que los actos cuenten con el permiso de Dios; cada persona, como ella misma señala, es libre de hacer lo que quiera, pero ella, desde luego, tiene claro que su libertad está condicionada por aquello que Dios dicte. Dicho de otro modo, podríamos afirmar que su libertad se sitúa allá donde se sitúan las prescripciones divinas. Pero además, Elena menciona que la primera condición para que el marido pueda ser polígamo es la obtención del permiso de la primera esposa. Es decir, que ella conoce las condiciones que van más allá de lo ético y, por tanto, en el caso hipotético de que su pareja quisiera ser polígamo, ella sabe que él tiene la obligación de consultarle en calidad de primera esposa.

Esta dimensión empoderadora, no obstante, no convierte la modalidad de acción pía en un modo de resistencia a la normatividad patriarcal islámica que, como hemos visto, impregna el discurso al que se adscriben Elena e Ihsan, como las personas del entorno de Alhambra. Más bien, es una dimensión que se desprende de la capacidad de acción pía que coloca el estudio del islam en el centro de la formación pía. Considero que si el conflicto sobre la poligamia se diera, la argumentación de Elena se fundamentaría sobre la base del respeto a las prescripciones divinas, no sobre la injusticia de género que ello pudiera entrañar. Sin embargo, es importante reconocer que, como mujer pía que cultiva el conocimiento del islam, Elena posee unas herramientas para negociar ciertas situaciones en que los privilegios patriarcales pudieran materializarse.

De manera similar, en y tras las reuniones de la mezquita Alhambra se produjeron algunos conflictos y conversaciones que me permitieron vislumbrar otras dimensiones empoderadoras del discurso y la capacidad de acción pía. Un día, asistió a una de tales reuniones una pareja compuesta por un árabe musulmán de nacimiento y una bilbaína no musulmana. En la presentación

10. Elena se refiere a la azora 4, aleya 129, en la que el Corán dice así: «No podréis ser justos (si sois polígamos) con vuestras mujeres, aún si lo deseáis. No seáis, pues, tan parciales que dejéis a una de ellas (la que no amáis) como en suspenso (ambiguo; ni con marido ni sin él). Si ponéis paz y teméis a Dios... Dios es indulgente, misericordioso» (Cortés 97). Este es un argumento frecuentemente aducido para rechazar la poligamia. 
ella dijo estar interesada en el islam y su voz no volvió a oírse hasta el final de la reunión cuando, inducida por su pareja, sentada lejos de ella por la segregación sexual que rige las reuniones, haciendo gestos y murmurando, preguntó si era islámicamente correcto llevar escote. Entonces tanto quien dirigía la reunión como algunas de las musulmanas asistentes se apresuraron a contestarle y, tras la charla en torno a la modestia sobre la que el código de vestimenta debería regirse en el caso de las mujeres, se hizo hincapié en que también los hombres deben vestirse de manera recatada ${ }^{11}$. Aunque las partes del cuerpo que deben taparse difieren según género, sigue siendo un aspecto normativo, se dijo, que muchos hombres musulmanes frecuentemente «olvidan» que tienen que cumplir.

A la salida, me quedé conversando con las asistentes, Ihsan y Elena entre ellas. Al poco comenzaron a comentar la escena arriba descrita y a hablar de cómo sospechaban que el chico traía a la chica para que se convirtiera al islam, cosa que no veían con buenos ojos porque la estaba, de alguna forma u otra, coaccionando, puesto que ella no parecía realmente interesada en el islam. Comentaron también que como él no parecía constituir un buen ejemplo en lo que al islam se refiere, ella tampoco iba a poder entender de manera correcta el mensaje divino. Prosiguieron denunciando la doble moral que consideraban caracterizaba al chico; este, sin dar un buen ejemplo islámico a su novia, quería «simplemente» que ella se convirtiera formalmente, seguramente para poder evitar la presión del entorno familiar musulmán. Además, pretendía que ella incorporase el código de vestimenta «adecuado» mientas que él no se aplicaba con el deber de cubrir las partes del cuerpo que a él le corresponde, como hombre, tapar.

Pero esta no fue la única ocasión en la que percibí la reivindicación de la igualdad que rige a las mujeres y los hombres en lo que a las obligaciones para con Dios se refiere. En otra ocasión, de vuelta de la reunión en la mezquita, las asistentes a Alhambra mostraron rechazo ante el caso de un chico que, sin ser practicante, estaba determinado a no casarse con ninguna mujer que no llevara niqab. Comentaron la doble moral de los hombres que sin tener din (religión; sin ser practicantes o «buenos musulmanes») quieren que su mujer vista «religiosamente». Ihsan manifestó que ella no querría, bajo ningún concepto, que su iman (fe o religiosidad) fuera mayor que la de su marido. En todo caso, dijo, aceptaría lo contrario para que él diera ejemplo. Ihsan parte de la idea de que es el hombre de la familia el que ha de desempeñar, en el contexto del

11. El feminismo islámico ha deconstruido este sesgo y el concepto de piedad feminista islámico, como ocurre con el feminismo cristiano, difiere sustancialmente del que se trata en el presente artículo. 
discurso patriarcal sobre la complementariedad que ella defiende, el papel de guía (espiritual). Con lo cual, desde dicho postulado, el grado de religiosidad o de piedad debe ser, cuanto menos, el mismo entre los cónyuges; y en caso de que alguien tenga que tener un mayor grado de piedad, ése deberá ser el guía, es decir, el hombre.

Estos relatos demuestran que hay algo que estas mujeres no piensan consentir, y es que los hombres, en general, y sus parejas musulmanas, en particular, se valgan de un doble discurso y praxis: pío y recatado para lo que les interesa (el recato en las mujeres) y no religioso para ellos mismos, como sucedía en los dos ejemplos mencionados. En este sentido, tanto Elena como Ihsan articulan un discurso de género en torno al eje de la piedad cuya lógica apela a los deberes que tanto hombres como mujeres tienen con respecto a Dios. Así pues, la reivindicación de la igualdad de hombres y mujeres en piedad no se refiere tanto a la injusticia intrínseca de las desigualdades de género como a la coherencia que tiene que haber entre lo interno y lo externo de cada persona con respecto a Dios, a su mensaje y a lo que se entiendan como sus prescripciones.

Estamos, pues, ante un paradigma de distinto cariz al que se presenta en el discurso de género de una mujer secular y progresista; o del de otras nuevas musulmanas entrevistadas que articulan un discurso islámico que deconstruye las bases patriarcales que sí operan en el discurso de Ihsan y Elena. Dentro de la formación y la consolidación de la identidad pía se forja un discurso de género que toma como principio central el cumplimiento que las personas, hombres y mujeres, deben hacer de las obligaciones de Dios. Tal y como sostiene el discurso islámico hegemónico y patriarcal del que beben Elena e Ihsan, las personas tienen obligaciones diferenciadas por género, pero ello no significa que los hombres no tengan las suyas. Las prescripciones divinas que guían la formación epistemológica, corporal y agencial de las sujetos pías, pues, pueden poner en tela de juicio los patriarcales privilegios masculinos.

\section{CONCLUSIÓN}

[H] llegado a la conclusión de que es necesaria cierta dosis de autoescrutinio y escepticismo con respecto a los compromisos políticos propios a la hora de comprender las vidas de las demás personas, que no necesariamente comparten dichos compromisos. (Mahmood xi)

A lo largo de las páginas precedentes he argüido que resulta necesario poner en tela de juicio la definición de agencia que los feminismos seculares han acuñado para poder realizar un acercamiento a unas mujeres que se sitúan fuera 
de paradigmas seculares y progresistas y poder comprender su cosmovisión, su modus vivendi, sus vidas, sus cuerpos y su discurso en la complejidad que presentan; y, una vez realizada esa deconstrucción y auto-vaciamiento, hacer una aproximación crítica y valorar hasta qué punto su modalidad de acción pía puede ser feminista. Así pues, he tratado de desligar el discurso y la capacidad de acción de las nuevas musulmanas pías que conocí y entrevisté del marco analítico y de los objetivos políticos del secularismo de raigambre liberal con el objetivo de comprender las bases, la lógica y las diferentes formas en que se manifiesta su modalidad de acción.

Espero haber podido ilustrar que la formación que realizan Ihsan y Elena en pos de erigirse en sujetos pías es intencionado y pasa por la in-corporación tanto externa como interna de los valores que según ellas conducen a la piedad. Entre los elementos clave en dicha formación pía he mencionado la disciplina, el (auto)control y la (auto)contención aplicados en el estudio y el acceso al conocimiento islámico, las relaciones íntimas y sociales, y su propia relación con Dios. La importancia de lograr las bendiciones divinas y el acercamiento a Allâh constituye la razón y el objetivo vital y espiritual de estas mujeres, y moldea su capacidad de acción. Las dimensiones de la modalidad de acción pía están, además, ligadas a sus biografías, sus experiencias, trayectorias y necesidades vitales, las cuales pueden ayudar a entender la validez explicativa que la piedad les ha ofrecido en la construcción y la interpretación del mundo. En este sentido, he destacado los elementos de género que dan cuerpo a su modalidad de acción, la cual he sostenido es profundamente política. Si partimos, como a lo largo de su amplia trayectoria el feminismo ha defendido, que no solo lo formal y lo público es político sino que también lo privado y lo personal lo es, se desprende la conclusión de que la sujeto pía es una sujeto política.

Las políticas de género que articulan las sujetos pías están atravesadas por una base patriarcal que no posibilita la gestación de discursos de género liberadores como los que construye el feminismo (el islámico o el secular). Sin embargo, existen dimensiones empoderadoras que pueden llevar a estas mujeres a rechazar o evitar las posibles situaciones de desigualdad de poder en las relaciones de género. Dichas ventanas de empoderamiento, además, solo pueden gestarse en el seno de los discursos y las modalidades de acción pías, puesto que se basan en la premisa de que los hombres, como las mujeres, tienen que cumplir con las prescripciones divinas. El discurso de género que tiene como eje la piedad no deja, por tanto, lugar a algunos privilegios que los hombres tradicionalmente han utilizado en su ostentación y ejercicio del poder sobre las mujeres: las pías rechazan contundentemente la doble moral 
de los hombres que desean, agradecen o incluso exigen algunos elementos píos en las mujeres mientras que no aplican en ellos mismos los referentes a los hombres. La concepción patriarcal del discurso islámico pío hace que las prescripciones divinas sean diferentes para cada género por la diferencia ontológica que se adscribe a mujeres y hombres; pero los hombres tienen las suyas y deben respetarlas.

Así pues, considero que las sujetos pías no son feministas por cuanto no se caracterizan por poseer una identidad feminista (no se reconocen como tales) ni por tener conciencia feminista (no se marcan unos objetivos que pretendan, consciente o inconscientemente, cambiar el sistema sexo-género). No obstante, existen en sus procesos de formación como sujetos pías unas dimensiones empoderadoras y de negociación de los privilegios masculinos que emanan del patriarcado. Es difícil valorar el punto hasta el que esta dimensión altera, realmente, el orden patriarcal. La fuerza del mismo reside principalmente en el carácter estructural y la complejidad de los mecanismos y las bases que sustentan la mayoría de ámbitos de conocimiento, incluido el discurso pío. No obstante, la modalidad de acción pía está lejos de ser algo uniforme, estático, aislado e inalterable y, por tanto, cabe esperar que el discurso de género pío vaya cambiando y ajustándose a las nuevas necesidades, también las relacionadas con lo que al género se refiere.

Dejar abierta la definición de capacidad de acción puede aportar, enriquecer y hasta transformar algunas de las certezas políticas y analíticas feministas. La parte prescriptiva y política del feminismo es la que nos lleva a imaginar, querer y reivindicar un mundo más justo, y la parte analítica del feminismo, teoría crítica por definición, la que nos lleva a rechazar unas fotografías analíticas simplistas que contribuyen a la opresión de ciertas personas y colectivos. Por eso, creo, es importante profundizar en las estrategias que usamos para ver y comprender la vida y, sobre todo, aquello que es ajeno a 'nuestro' modo de entenderla. De esta manera, podremos situarnos en un lugar más realista, respetuoso y crítico con quien no comparte unos postulados feministas, también podremos profundizar en el autocuestionamiento que debe preceder a la crítica hacia fuera, y evitar caer en binomios y categorizaciones falaces que reduzcan esa mirada crítica que caracteriza al feminismo. 


\section{REFERENCIAS BIBLIOGRÁFICAS}

Andújar, Natalia. «¿Es el etnocentrismo malo para las mujeres?». Pikara Magazine. http://www.pikaramagazine.com/2016/06/es-el-etnocentrismo-malo-para-lasmujeres/\#sthash.IjHkT0OK.dpuf, consultado el 26/06/2016.

Badran, Margot. «Feminism and Conversion: Comparing British, Dutch, and South African Life Stories». Women Embracing Islam: Gender and Conversion in the West. Ed. Karin Van Nieuwkerk. Austin: University of Texas Press, 2006, 192-229.

Cortés, Julio. El Corán. Barcelona: Herder Editorial, S.L., 2005.

Del Olmo, Margarita. «El velo de la discordia: un análisis del reflejo de la sociedad española en el velo de una conversa». SOCIOTAM 11, 1 (2001): 9-28.

Del Olmo, Margarita. «Los conversos españoles al islam: de mayoría a minoría por la llamada de Dios». Anales del Museo Nacional de Antropología 7 (2000): 15-39.

Foucault, Michel. Historia de la sexualidad. Vol. 1. Méjico D.F. y Buenos Aires: Siglo XXI, 2005 [1977].

Gil, Silvia L. Nuevos feminismos: sentidos comunes en la dispersión. Madrid: Traficantes de Sueños, 2011.

Mahmood, Saba. Politics of Piety: The Islamic Revival and the Feminist Subject. New Jersey: Princetown University Press, 2005.

Mijares, Laura; Ramírez, Ángeles. «Mujeres, pañuelo e islamofobia en España: un estado de la cuestión». Anales de Historia Contemporánea 24 (2008): 121-135.

Moreras, Jordi: «Prólogo: nuevas voces y nuevas vías para el islam europeo». El islam minoritario: cómo ser musulmán en la Europa laica. Tariq Ramadan. Barcelona: Edicions Bellaterra, 1999, 13-38.

Prado, Abdennur. El islam como anarquismo místico. Bilbao: Virus editorial/Lallevir, 2010.

Zine, Jasmin. «Between Orientalism and Fundamentalism. The Politics of Muslim Women's Feminist Engagement». Muslim World Journal of Human Rights 3, 1, 5 (2006): 1-24. 
